\title{
Quantifying physical activity in daily life with questionnaires and motion sensors in
} COPD

\author{
F. Pitta*,\#, , T. Troosters*,\#, V.S. Probst ${ }^{\star * \#}$, M.A. Spruit*, \\ M. Decramer,*\# and R. Gosselink ${ }^{\star * \#}$
}

ABSTRACT: Accurate assessment of the amount and intensity of physical activity in daily life is considered very important due to the close relationship between physical activity level, health, disability and mortality. For this reason, assessment of physical activity in daily life has gained interest in recent years, especially in sedentary populations, such as patients with chronic obstructive pulmonary disease (COPD).

The present article aims to compare and discuss the two kinds of instruments more commonly used to quantify the amount of physical activity performed by COPD patients in daily life: subjective methods (questionnaires, diaries) and motion sensors (electronic or mechanical methods). Their characteristics are summarised and evidence of their validity, reliability and sensitivity is discussed, when available.

Subjective methods have practical value mainly in providing the patients' view on their performance in activities of daily living and functional status. However, care must be taken when using subjective methods to accurately quantify the amount of daily physical activity performed. More accurate information is likely to be available with motion sensors rather than questionnaires. The selection of which motion sensor to use for quantification of physical activity in daily life should depend mainly on the purpose of its use.

KEYWORDS: Accelerometer, chronic obstructive pulmonary disease, motion sensor, physical activity, questionnaire, review

ifestyle, including physical inactivity in daily life, plays an important role in terms of disability and mortality. The fact that regular physical activity may prevent or delay the onset or progress of different chronic diseases is now well recognised [1]. For instance, it is known that in patients with chronic obstructive pulmonary disease (COPD), lower levels of physical activity in daily life are related to higher risk of hospital readmission [2] and shorter survival [3]. Therefore, assessment of the amount and intensity of physical activity in daily life is considered very important due to the close relationship between activity levels and health [4].

Patients with COPD frequently show symptoms such as dyspnoea and fatigue, which lead to functional impairment and disability. Most of the patients with severe COPD are breathless even when performing simple activities of daily living
(ADL) or walking around at home [5]. In addition, stable non-oxygen-dependent COPD patients are much less active in daily life when compared with healthy elderly people [6], and oxygen-dependent patients are even less active [7]. Therefore, limited physical activity level is a reflection of the subject's deconditioning and symptoms such as dyspnoea. However, inactivity itself contributes to a further worsening of the physical condition of the subject, and to even more dyspnoea. This configures a vicious circle of inactivity, deconditioning and dyspnoea that has frequently been mentioned in the literature $[8,9]$. Consequently, although inactivity can be primarily understood as a consequence of the disease, it can also be a cause of the disease's worsening and progression. Referring to this "COPD vicious circle", the report of the Global Initiative for Obstructive Lung Disease (GOLD) states that "these problems have complex

\section{AFFILIATIONS}

*Respiratory Rehabilitation and Respiratory Division, University Hospitals, and

\#Faculty of Kinesiology and Rehabilitation Sciences, Katholieke Universiteit Leuven, Leuven, Belgium. "Dept of Physiotherapy, Universidade Estadual de Londrina, Londrina, Brazil.

CORRESPONDENCE

R. Gosselink

Respiratory Rehabilitation and Respiratory Division University Hospital Gasthuisberg Herestraat 49

B-3000 Leuven

Belgium

Fax: 3216347126

E-mail: Rik.Gosselink@

uz.kuleuven.ac.be

Received:

June 012005

Accepted after revision:

December 182005

SUPPORT STATEMENT

F. Pitta is supported by Coordenação de Aperfeiçoamento de Pessoal de Nível Superior (CAPES; Brasilia, Brazil). T. Troosters is a postdoctoral fellow of the Fonds voor Wetenschappelijk Onderzoek (FWO; Vlaanderen, Belgium). M.A. Sruit is a postdoctoral fellow at Katholieke Universiteit Leuven, Leuven, Belgium (PDM/04/230).

European Respiratory Journal Print ISSN 0903-1936 Online ISSN 1399-3003 
interrelationships and improvement in any one of these interlinked processes can interrupt the vicious circle in COPD so that positive gains occur in all aspects of the illness" [8]. Therefore, interventions which may help to increase daily physical activity have the potential to break the vicious circle and lead to relevant improvements [10, 11]. For all these reasons, assessment of physical activity in daily life and functional status in COPD patients has gained interest in recent years, and the body of literature has grown considerably.

The present review aims to describe and compare the two kinds of instruments more commonly used to quantify the amount of physical activity performed by COPD patients in daily life: subjective methods (questionnaires, diaries) and motion sensors (electronic or mechanical methods). This review includes instruments that have already been used in studies involving patients with COPD, and popular instruments that can potentially be applied in this population. Their characteristics are summarised and evidence of their validity, reliability and responsiveness are discussed, when available.

\section{METHODS}

Using Medline, a literature search was carried out of the last 15 yrs and was finalised in November 2005. References of the relevant studies in the same period were also checked. Strategy of search consisted of the combination of the terms "COPD and physical activity" with the terms "assessment", "measurement", "quantification", "questionnaire", "scale", "diary", "motion sensor", "accelerometer" and "activity monitor". Methods aiming to assess functional status [12-16], selfefficacy, performance and independence during ADL [17-27] and the impact of symptoms in usual activities [28-30], as well as health-related quality of life questionnaires with subscales of physical activity [31-33] and methods to assess functional exercise capacity $[34,35]$, are not discussed in the present review, since they do not aim primarily to quantify the amount and intensity of activity performed in daily life. There were no limitations in terms of study design and sample size, but only articles published in English were included.

The prices of motion sensors mentioned in the present review were obtained through the manufacturers' websites as accessed in the first week of August 2005. In case the price was not found this way, the manufacturer was contacted by email and asked to provide the current commercial price correct in August 2005. If no answer was obtained, the price was described as "could not be retrieved". Prices of the different devices which are described in this review do not include extra costs, such as shipping and training.

\section{DEFINITION OF PHYSICAL ACTIVITY IN DAILY LIFE}

Physical activity is considered "any bodily movement produced by skeletal muscles that result in energy expenditure" [36]. Therefore, physical activity in daily life (or daily physical activity) can be considered "the totality of voluntary movement produced by skeletal muscles during everyday functioning" [37].

\section{HOW TO QUANTIFY PHYSICAL ACTIVITY}

Physical activity in daily life can be quantified by direct observation, assessment of energy expenditure and the use of physical activity questionnaires and motion sensors.

\section{Direct observation}

Direct observation is carried out by observers who watch or videotape activities performed by the subjects and quantify them [38]. This technique is often used in children, since other techniques are difficult to apply in this population. However, it is very time-consuming, intrusive and demanding, and therefore not suitable for large populations.

\section{Energy expenditure}

Total energy expenditure is divided into three components: resting metabolic rate, diet-induced energy expenditure and physical activity energy expenditure. Although physical activity in daily life is sometimes expressed or quantified as physical activity energy expenditure, these terms are not synonyms. Physical activity energy expenditure is "a measure of energy cost of physical activity" [39] or, in other words, the quantification of the energy spent on physical activities. Methods to assess energy expenditure include calorimetry and the doubly labelled water (DLW) method. The fact that energy spent on physical activity depends on factors such as body mass, movement efficiency and energy cost of the activities [39, 40] may hinder the use of energy expenditure assessment methods, such as DLW, to compare the amount of physical activity performed by different individuals [39]. Furthermore, the high cost is an important limitation of this method. A review with details of this method can be found elsewhere [41]. It is worthwhile underlining that assessment of physical activity energy expenditure does not quantify the duration, frequency and intensity of physical activity performed.

\section{Scope of this review}

The literature highlights that direct observation of activities and the energy expenditure assessment (DLW and calorimetry) are criterion methods that are accepted worldwide (or gold standards) [42] in the quantification of physical activities in daily life. However, due to their limitations, these methods are unlikely to be used in the clinical practice or in studies involving large populations, and for these reasons will not be discussed more extensively. Nonetheless, they are mentioned in this review as criterion methods for validation of questionnaires and motion sensors. These are the more common and accessible methods with which to quantify physical activity in daily life, and will be discussed in detail in the following sections of this review.

\section{QUESTIONNAIRES (SUBJECTIVE OR SELF-REPORTED METHODS) \\ Characteristics}

Quantifying physical activity in daily life through questionnaires and diaries has the advantage of being inexpensive and easy to apply. This has led to the widespread use of these methods to gain insight into physical activity habits. However, these techniques are known to depend on the following factors, which may induce inaccuracy or bias in the assessments.

1) Accurate perception and recall of information by the subject. For instance, difficulties may be found when recalling light activities [43] (slow walking at home, self-care, gardening, home management, dressing, etc.), particularly over long periods of time. Questionnaires recall physical activities

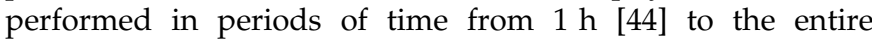


lifetime $[45,46]$. Due to limitations in memory, the reliability of information generally decreases with the length of the period surveyed [47].

2) The questionnaire's design. Questionnaires with an interval response option (e.g. how many days in a week walking is performed) showed higher self-reported amounts of physical activity when compared to "open" questions [48]. Additionally, simple questionnaires generally show the highest coefficients of reliability and validity, since subjects may become bored and/or confused by long questionnaires [47, 49].

3) Individual characteristics such as age, cultural factors, work status and cognitive capacity [50-54].

4) The table of energy costs used in case the outcomes of questionnaires and diaries are converted into an estimate of energy expenditure. Energy cost of different activities varies substantially among subjects as it depends on factors such as body mass and movement efficiency [39, 42], and not all activities carried out in daily life have a known energy cost.

An overview of the subjective methods used to quantify physical activity in daily life in COPD patients is presented in table 1.

\section{Reliability}

Reliability (or test-retest reliability, or reproducibility) can be understood as the ability of an instrument to yield correlated results when applied to the same population under similar conditions on at least two successive occasions [77]. In the case of questionnaires, special attention has to be given to the fact that different results can be achieved if different interviewers are applying the questionnaire. Lack of reliability may be present, especially in populations characterised by low-intensity activities [78] and in long test-retest intervals [79-81].

None of the studies which used questionnaires to quantify physical activities specifically in COPD patients (table 1) investigated test-retest reliability. The results described below concern only administration of these questionnaires in the general elderly population. The Physical Activity Scale in the Elderly (PASE) showed good test-retest reliability coefficient over a 3- to 7 -week interval $(0.75$; $95 \%$ confidence interval 0.69 $0.80)$ [72]. Reliability for mail administration $(r=0.84)$ was higher than for the telephone administration $(\mathrm{r}=0.68)$. VOORRIPS et al. [56] investigated the reliability of the Baecke's questionnaire and found a Spearman's correlation coefficient of 0.89 over a test-retest interval of 20 days.

Populations involved in studies investigating the reliability of the Minnesota Leisure Time Physical Activity Questionnaire (Minnesota LTPA Questionnaire) [51, 82-84] were mainly composed of adults and middle-aged subjects, with no specific investigation in elderly people. Results showed very discrepant correlations ranging -0.04-0.92, with higher values corresponding to a shorter time interval between tests. Reliability of the Minnesota LTPA Questionnaire may be hindered in elderly people because it requires recall of activities over the past 12 months, which may be particularly difficult in this group of individuals. The Zutphen Physical Activity Questionnaire (ZPAC) [75, 76] showed good testretest reliability in a general elderly sample, although the reliability worsens in the oldest patients and in those with cognitive impairment [85].

It is important to notice that low test-retest reliability of questionnaires, as well as in the case of motion sensors, cannot be confounded with the variability in the subject's daily physical activity. Day-to-day variability in habitual physical activity may be largely due factors such as age and employment status [86, 87]. Therefore, a questionnaire cannot be considered unreliable if low test-retest reliability is observed; this may be due to variation in the physical activity performed by the subject, and not a result of lack of reliability of the questionnaire. In addition, seasonal variations in physical activity occur [81], and this has to be taken into consideration when assessing physical activity in daily life.

\section{Validity}

A classic definition of validity is the assessment of whether an instrument measures what it intends to measure [77]. Validity has different components, but the instrument should ideally be validated in terms of criterion validity, i.e. a combination of predictive value and concurrent validity. This indicates the correspondence of the instrument's score to a more precise assessment, the criterion method (gold standard). However, due to the difficulties in applying the gold standard methods in large populations, other methods to assess physical activity have been used to investigate questionnaires' validity (e.g. motion sensors, other physical activity questionnaires and oxygen consumption). Special attention should be given to cultural factors if a questionnaire has been translated into another language [88]. In addition, the literature shows that most physical activity questionnaires are correlated with the outcomes of the criterion methods of high-intensity physical activity, but not in light- or moderate-intensity activity [49]. This is a potential problem when these questionnaires are used in more disabled patient populations, who are not characterised by performing physical activities at high intensity.

When diary-reporting the daily time spent on different activities [44], COPD patients significantly overestimated time spent walking and underestimated time spent standing [66]. Validity of the Baecke, Minnesota LTPA and PASE questionnaires although not specifically studying COPD patients, was investigated in a number of different populations (table 1). The Minnesota LTPA was shown to significantly underestimate physical activity energy expenditure in elderly people [89]. The ZPAC was used in the study by SLINDE et al. [76] to describe the small amounts of detectable physical activity in COPD patients. However, an issue raised by the authors is that a questionnaire like the ZPAC is only able to assess a certain amount of the patients' total time in activity, and not the whole active time. This limits its use for accurately determining the amount of physical activity performed and, consequently, to predict the total daily energy requirement.

Although no specific validation study of the Baecke questionnaire was performed in COPD, this questionnaire was used in three different studies [57-59] in which COPD patients had approximately the same airflow obstruction (forced expiratory volume in one second (FEV1) ranging an average $36-41 \%$ predicted) and normal body mass index. In these studies, patients from three different countries (Spain, France 


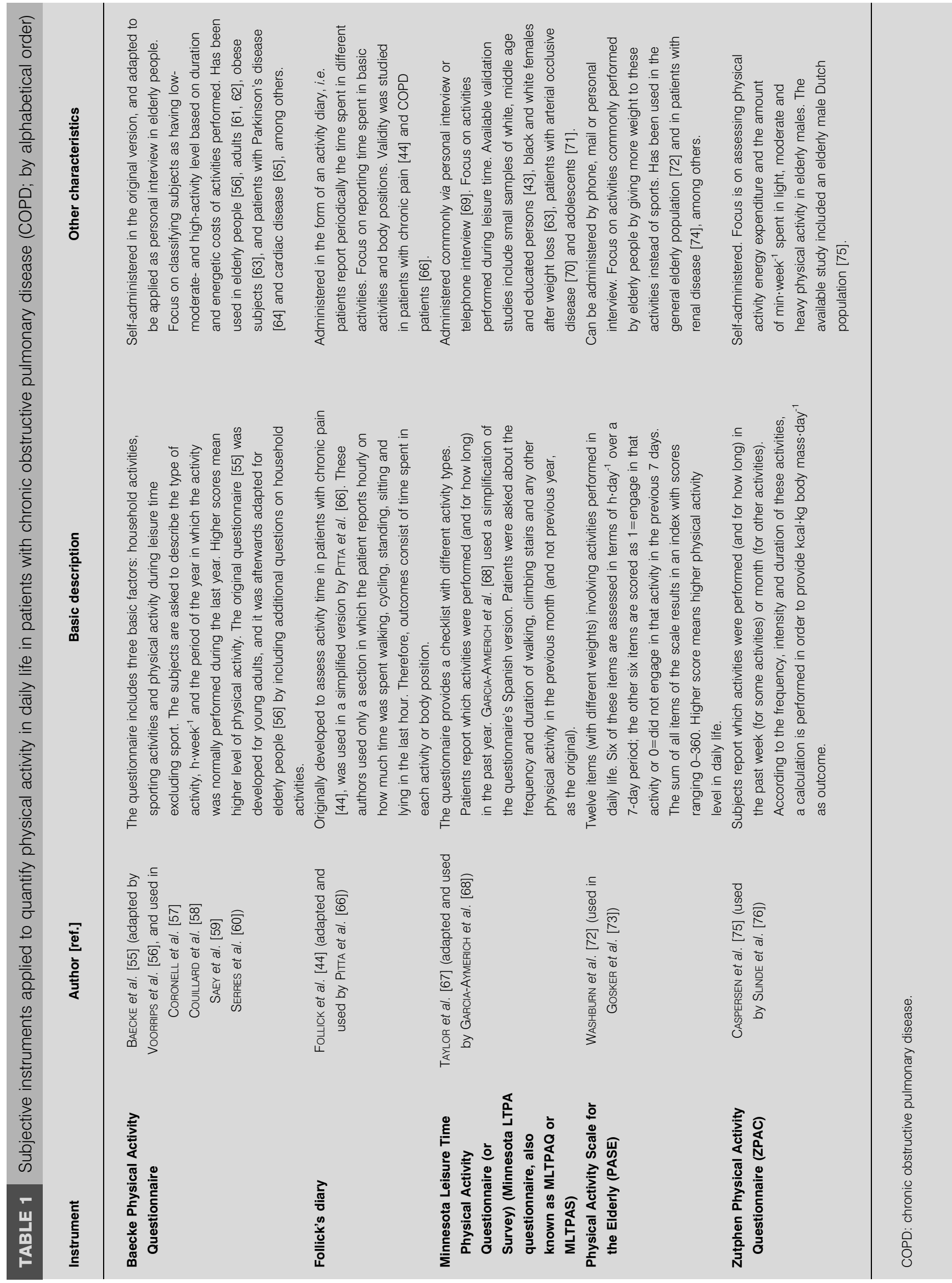


and Canada) were assessed using the questionnaire. Patients from Spain, who had the lowest FEV1 (average 36\% pred), showed approximately double the physical activity score (13.1 \pm 6.2 points) [57] when compared with patients from Canada $(6.4 \pm 3.4)$ [59] and France (7.6 \pm 1.9$)$ [58]. This suggests that either physical activity in daily life is largely different between these populations, or the questionnaire has limited validity in COPD patients. Further research is necessary to better explain these findings.

Concerning the PASE questionnaire, SCHUIT et al. [90] studied its validity against energy expenditure assessed by DLW, showing a correlation of 0.58 (95\% confidence interval: 0.50 0.81 ) between the outcomes of these two methods. Correlation between PASE questionnaire scores and output from the Actigraph (CSA) or MTI/CSA (MTI Health Services, Ft Walton Beach, FL, USA) in an elderly population in free-living conditions was more modest $(\mathrm{r}=0.42 ; \mathrm{p}<0.01)$ [91].

Although mean differences between subjective methods and objective gold standard methods may not be large in a group basis, the individual variability is large both in COPD patients [66] and in the general elderly population [89]. Hence, the use of subjective methods as estimates of daily physical activity on an individual basis is not recommended. Discrepancies between self-reporting methods and objective assessments were also reported in different populations [63, 92-96].

\section{Responsiveness}

When assessing physical activity in daily life, responsiveness (also called sensitivity) of a tool can be understood as its capacity to detect relevant changes over time that are known to occur [97]. It has been suggested that good responsiveness of an instrument should join reliability and validity as necessary requirements for instruments designed primarily to measure change over time [98].

None of the studies that used questionnaires to quantify physical activity in COPD patients investigated their responsiveness to improvements in amount and intensity of physical activity in daily life after interventions. Other questionnaires aiming to assess other aspects of physical activity in daily life (functional status, activities of daily living and quality of life related to physical activity) were responsive to changes after pulmonary rehabilitation programmes [18, 19, 27, 37, 99].

\section{Other potentially useful physical activity questionnaires}

Besides the questionnaires already mentioned in this review as being used with COPD patients (table 1), a number of other available questionnaires aim at quantifying physical activity in daily life and might potentially be used in this population. Detailed information on these various physical activity questionnaires can be found in an extensive review by PEREIRA et al. [100]. A summary of the characteristics of some widely known questionnaires follows.

College Alumni (or alumnus) questionnaire, also know as Harvard Alumni questionnaire or Paffenbarger Physical Activity questionnaire

In this questionnaire [101, 102], the individual is asked about duration and frequency of walking, stair climbing, recreation and sports played in the past week or year. The questionnaire may be self or interviewer administered. A number of studies used this questionnaire to investigate the relationship between physical activity and various factors such as risk for cardiovascular disease [103], stroke [104], diabetes [105], cancer [106], hypertension and all-cause mortality [107].

\section{Tecumseh Occupational Physical Activity questionnaire}

The Tecumseh questionnaire [108, 109] is self or interviewer administered, and assesses physical activity performed in the past year. It focuses on work activities, i.e. energy expenditure during the workday and during transportation to and from work. A recent study showed that the combination of the Tecumseh questionnaire with the Minnesota LTPA Questionnaire was useful to estimate mean energy expenditure in employed adult males [110].

\section{Stanford Seven-Day Physical Activity and Stanford Usual Activity} questionnaires

Although these two interviewer-administered questionnaires were developed by the same group, they have different designs and have been considered separately [46, 47]. The Stanford Seven-Day Physical Activity questionnaire (also known simply as Stanford Seven-Day Recall) [111] focuses on time spent doing several physical activities and sleeping for the past 7 days. A version of this questionnaire adapted to telephone interview has been developed [112]. The Stanford Usual Activity questionnaire [113] uses a different time frame (the past 3 months) and focuses on moderate and vigorous activities. In a validation study of five questionnaires against a uniaxial accelerometer in healthy adults, the Stanford SevenDay Recall had the best correlation coefficient $(r=0.79)$ [114]. In addition, a large validation study in healthy elderly people including 10 questionnaires showed that only the Stanford Usual Activity questionnaire, the Stanford Seven-Day Recall score and the College Alumni sports score had significant correlations with total energy expenditure assessed by DLW [47].

\section{Conclusions}

Patients with COPD are able to appropriately report the perceived limitations and symptoms related to their disability in questionnaires aiming at these outcomes. However, concerning instruments applied specifically to quantify duration, frequency and intensity of physical activity performed in daily life, caution is necessary. Although the results of these subjective methods may be useful as a group estimate, their lack of accuracy and large individual variability indicate that relying on them on an individual basis is not recommended. Results from physical activity questionnaires better reflect heavy-intensity physical activity than light- or moderateintensity activity, which does not favour their use in chronically disabled populations, such as COPD patients.

Just a few instruments aimed at quantifying physical activity in daily life were used in COPD patients. Evidence concerning reliability, validity and responsiveness of these few instruments in COPD patients is still lacking, since these aspects were poorly studied specifically in this population. Among these, the ones with better-documented validation in elderly and other populations are the Minnesota LTPA Questionnaire, the Baecke questionnaire and the PASE questionnaire. Some questionnaires had not been used in COPD, but might be 
potentially useful since they performed better than others in validation studies with other chronically disabled or with elderly populations (e.g. Stanford Seven Day Recall, Stanford Usual Activity and College Alumni questionnaires).

\section{MOTION SENSORS (ELECTRONIC OR MECHANICAL METHODS)}

\section{Characteristics}

Great attention has recently been given to objective monitoring of daily physical activity in different populations [39, 115-119], including patients with COPD [37]. Motion sensors are instruments used to detect body movement, which can be used to objectively quantify physical activity in daily life over a period of time. These instruments basically include pedometers (measurement of steps) and accelerometers (detection of body acceleration). An overview of the devices used in investigations with COPD patients is presented in table 2.

Pedometers are small, simple and inexpensive instruments. They are usually worn on the waist and contain a horizontal, spring-suspended lever arm that deflects with vertical acceleration of the hips during walking (the up-and-down motion during ambulation). Since pedometers were designed to detect vertical movement, they most logically assess number of steps. The output from the device is easily understood as a motion count, representing a step. Nevertheless, any movement in the vertical plane, like getting up from a chair, can be eventually detected and will also result in a motion count [120]. The use of pedometers has been promoted to stimulate and monitor walking in the general population, since it is suggested that 10,000 steps per day could be effective for prevention of disease and promotion of a healthier lifestyle [132, 133]. In public health campaigns to increase physical activity levels, pedometers are useful tools because they can be easily worn to determine whether an individual is reaching step recommendations [134]. Disadvantages of these devices include the tendency to underestimate very slow walking [135] and the fact that some devices require that the subjects periodically write down the output of the assessment in case of multiple days of measurement. Moreover, only limited data are provided (counts, distance estimate), with no information about pattern of physical activity and time spent in different activities over the day, as well as the intensity at which these activities are performed.

TUDOR-LOCKE et al. [136] compared a pedometer (Yamax DigiWalker 200; YAMAX USA, Inc., San Antonio, TX, USA) with a uniaxial accelerometer (CSA accelerometer; MTI Health Services) and found a significant difference in mean step counts between the devices. This difference was attributed to a higher threshold of vertical acceleration required to record a step in the Yamax Digi-Walker $200(0.35 \times g$ for the pedometer versus $0.30 \times g$ for the accelerometer). In other words, the pedometer was less sensitive than the accelerometer to detect walking. It appears that most pedometers require even higher vertical acceleration as a threshold to detect a step $(0.50 \times g)$ [137].

Accelerometers are technologically more advanced devices that allow the quantity and intensity of movements to be determined [37]. These devices are able to store data continuously over long periods of time, and the monitors must be worn without interference in the subject's normal pattern of activities. Accelerometers are basically of two kinds: uniaxial and multiaxial. Uniaxial sensors detect motion in only one body dimension (or plane), and may be inaccurate for activities with static trunk movement, such as cycling and rowing [138]. The information provided is comparable to a pedometer, but with the advantages of assessing movement intensity and allowing more detailed analysis in different time frames. Multiaxial devices are able to detect motion in more than one plane of movement. Some multiaxial devices are able to detect a variety of body positions and physical activities, and are often denominated activity monitors. A major advantage of multiaxial accelerometers is that these devices are able to provide more detailed information than the previously mentioned types of motion sensors. Disadvantages of accelerometers include the higher costs compared with pedometers and the need for technical expertise and additional hardware/software to analyse the data (although not in all cases: see table 2 and Other potentially useful motion sensors). In addition, these devices may be sensitive to vibrational artefacts, for example, recording vibration related to being in a vehicle $[139,140]$. A limitation of motion sensors worn on the waist, hip or ankle is that activities of the upper extremities of the body are not measured. Another general concern about motion sensors is the subject's compliance to the measurement, although assessments require only slight care from the patients (e.g. remembering to put the device on, positioning it correctly, avoiding shocks, checking battery level). In the study by KOCHERSBERGER et al. [141], 20\% of a sample of elderly subjects did not comply with wearing an accelerometer. These findings are in line with a study in COPD patients, which showed that $19 \%$ of the subjects had to be excluded from the study due to non-compliance or technical issues (e.g. battery problems) [6].

\section{Reliability}

Analysing the test-retest reliability of a pedometer (Fitty 3; Kasper \& Richter Company, Uttenreuth, Germany), SCHONHOFER et al. [120] found no significant differences in mean daily movement from test-retest results taken 4 weeks apart in a COPD population; the correlation between outputs in the two assessment points was 0.94. STEELE et al. [127] evaluated the reliability of a triaxial accelerometer (Tritrac R3D Research Ergometer; Professional Products, Madison, WI, USA; StayHealthy Inc., Monrovia, CA, USA) during three sequential 6-min walk distances (6MWDs). The intraclass correlation coefficient (ICC) during the walking tests was 0.84 , and adequately reflected the improvement with each successive walk due to the learning effect of the test. However, variability between devices within the same model may be present. In the study by SCHONHOFER et al. [120], two pedometers of the same manufacturer and model were worn simultaneously. Devices from four different manufacturers were tested, and reliability was considered acceptable if the two devices differed by $<10 \%$. Only one manufacturer produced pedometers that met this level of reliability (Fitty 3 ; table 2). In addition, when analysing 20 pedometers of this same model, four did not match the performance of the reference instrument and were discarded. A study with the Tritrac RT3 triaxial accelerometer also concluded that intermonitor variability exists [142]. It is advisable to test the reliability of the chosen device, and to use the same 


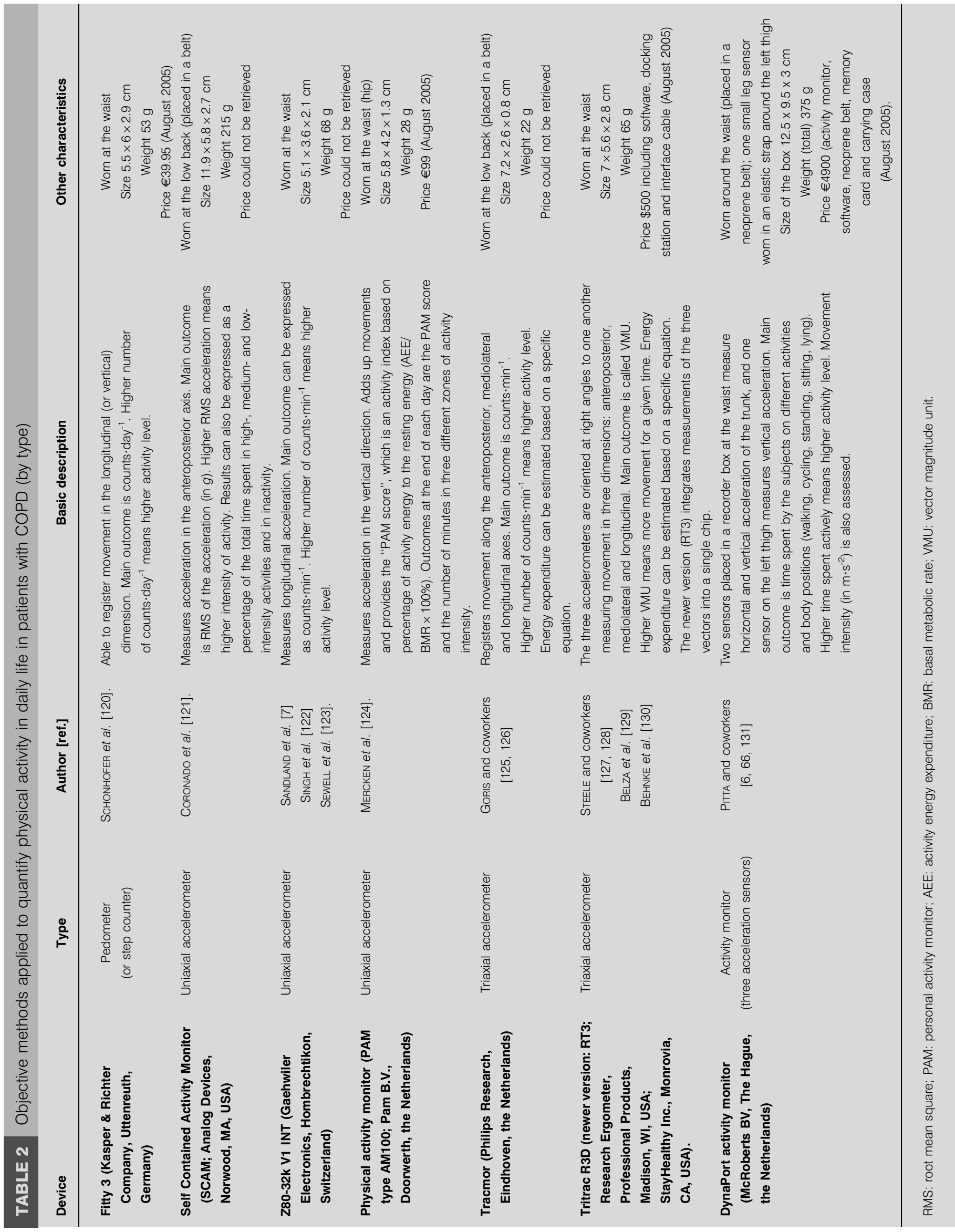


device in repeated measures, as well as to perform adequate calibration according to the manufacturer's specifications (in case calibration is allowed).

Assessment with the DynaPort activity monitor (McRoberts BV, The Hague, the Netherlands) during 5 days in COPD patients showed that this population has as much day-to-day variability in walking time as healthy elderly people, despite the lower physical activity level (coefficient of variation of $\sim 26 \%$ ) [6]. This has potential repercussions for longitudinal studies which aim to detect relatively small differences after interventions. Therefore, in longitudinal studies, it seems advisable to obtain more days of assessment to reduce the chance of having a type II error.

\section{Validity}

The output of pedometers is highly representative of that produced by uniaxial accelerometers in healthy subjects in free-living conditions [136], although this was never shown in COPD patients. These two instruments basically detect movement in the vertical plane and give, not surprisingly, comparable results. Output from pedometers used in adult healthy subjects was also highly correlated to outputs from triaxial accelerometers [50]. However, pedometers do not measure the intensity of bodily movement. This leads to the general idea that pedometers have lower accuracy in populations characterised by slow walking and inactivity [143], which is the case in COPD patients [6]. In addition, its accuracy may vary with deviations from a normal gait pattern [144]

Accelerometers are more sensitive to detection of physical activity differences in relatively inactive populations, and detect physical activity periods better than subjective methods $[93,94]$. In addition, they are more sensitive to light activities $[37,116]$. Concerning validity of accelerometers as a measure of daily activity in COPD patients, output of the Tritrac R3D triaxial accelerometer correlated well with the 6MWD $(\mathrm{r}=0,74$; $\mathrm{p}<0.001)$ [127]. The uniaxial accelerometer Z80-32k V1 INT (Gaehwiler Electronics, Hombrechtikon, Switzerland) was able to distinguish between brisk walking and other types of domestic activities in a COPD population [122]. Recently, an accelerometer-based activity monitor (DynaPort) was shown to be as accurate as the gold standard (video recordings) for assessment of time spent walking, cycling, standing, sitting and lying down in daily life in COPD patients [66]. ICC between outcomes from DynaPort and video recordings were between 0.999 for walking time and 0.750 for lying down time. In addition, changes in the intensity at which walking was performed were also accurately detected by the device. Therefore, it is an instrument that is able to measure both the total amount and intensity of spontaneous activities performed throughout the day in the subject's own environment. The SelfContained Activity Monitor (SCAM; Analog Devices, Norwood, MA, USA), a uniaxial accelerometer used in the study by CORONADO et al. [121], was not validated specifically in the COPD population. In overweight adult females [145], the device showed high correlation between accelerometer output and speed during treadmill walking $(\mathrm{r}=0.95 ; \mathrm{p}<0.01)$ and short unconstrained walks $(r=0.86 ; \mathrm{p}<0.01)$.

Regarding the capacity to distinguish different physical activity levels between subjects (or groups of subjects), the
DynaPort activity monitor, the Z80-32k V1 INT accelerometer and the Fitty 3 pedometer were able to detect significant differences between COPD patients and healthy controls [6, $120,122]$. In addition, the DynaPort and the Z80-32k V1 INT were also able to distinguish fast from slow walking in COPD patients $[66,122]$. In healthy subjects, it was suggested that a uniaxial accelerometer (Caltrac; Muscle Dynamics, Torrance, CA, USA) did not have the capacity to reflect differences in physical activity levels [146]. However, triaxial devices showed the capacity to discriminate low, moderate and high overall activity levels [147] or to categorise individuals as sedentary, moderately active or active [141].

The number of assessment days may play an important role when measuring physical activity in daily life. In COPD patients, there is evidence that 2 days of assessment with an activity monitor provides an acceptable intraclass reliability coefficient (IRC >0.70) in order to differentiate COPD patients and healthy elderly people, although more days of assessment provide a higher coefficient [6]. In healthy adults, reports in the literature are discrepant and suggest that the number of days necessary to achieve an acceptable IRC may range from $\geqslant 3$ to $\geqslant 7$ days [148-150]. Although the number of days possibly depends on the characteristics of the population studied and the reliability of the device used, it seems that one single assessment day is not acceptable both for healthy adults [151] and for COPD patients [6].

GORIs et al. [125] showed the validity of a triaxial accelerometer (Tracmor; Philips Research, Eindhoven, the Netherlands) combined with assessment of basal metabolic rate in order to estimate energy expenditure. The authors developed formulas to calculate energy expenditure based on the output of the accelerometer plus estimation or measurement of basal metabolic rate. They validated these formulas against DLW, concluding that there were no significant differences between the methods (an average difference of $2.7 \pm 8 \%$ ). In healthy subjects, it has been shown that the accelerometer's output is significantly correlated to energy expenditure [152, 153], although this was never shown in COPD patients. However, the literature shows conflicting results concerning the accuracy of energy expenditure estimation using accelerometers [143, 154-157], with some studies suggesting underestimation and others overestimation. This illustrates the limitations of using accelerometry to estimate energy expenditure in daily life. It has been suggested that accelerometers are more accurate for quantification and differentiation of body movements than for estimation of energy expenditure, especially at slow speeds [158]. Plasqui et al. [159] have recently shown that triaxial accelerometers are superior to uniaxial devices when estimating energy expenditure. Therefore, in order to improve accuracy, the use of triaxial accelerometers is indicated. In addition, there is evidence that the combination of heart rate monitoring with body movement registration improves the precision of energy expenditure assessment [160-162], although this has not been shown in subjects with slow walking speeds, such as COPD patients.

\section{Responsiveness}

The available studies aimed at investigating changes in the amount of daily physical activity after pulmonary rehabilitation assessed by motion sensors in COPD showed conflicting 
results. Two studies showed either very modest or no improvement in the motion sensors' output after programmes lasting 3 and 8 weeks [121, 128]. However, it is not clear whether the modest changes shown by these studies derive from methodological issues of the assessment method (e.g. the outcomes used) or from lack of improvement by the patients due to characteristics of the rehabilitation programs applied (e.g. duration, intensity, frequency). In contrast to the aforementioned studies, two other studies found significant improvements after programs of 7 and 8 weeks of duration $[123,124]$. Differences in the programs used and in the populations involved may explain the conflicting results. Available evidence shows that, in chronically ill patients, daily physical activity may not change significantly after exercise training programmes; this is clearly due to lack of improvement and not methodological issues. A study in patients with severe heart failure showed that daily energy expenditure was not improved after exercise training when measured both with an accelerometer (Caltrac) and with the gold standard method, DLW [163]. These findings are not in favour of the hypothesis that improvements were not captured by the accelerometer, but rather suggest that the programme did not result in significant changes in daily energy expenditure. Furthermore, even if the amount of physical activity does not increase, rehabilitation may have still been beneficial because existing activity may have become easier and resulted in less breathlessness [27]. However, methods used to objectively quantify the amount and intensity of physical activity performed in daily life are not able to detect if physical activity is more easily performed or results in less breathlessness. This is subjective and requires specific instruments (questionnaires, in this case) which aim at investigating symptoms and performance during activities of daily living or exercise [18, 19, 22, 27]. It is therefore suggested that objective methods for assessment of daily physical activities and subjective methods for assessment of functional status or ADL have complementary roles in assessing disability in COPD patients [39]. It also has to be taken into consideration that the patients themselves may not aim at increasing daily activity as a primary objective [164].

Some issues concerning the responsiveness of motion sensors to changes after interventions deserve consideration. First, some activities performed during exercise programmes and during daily life which do not include total body movement, such as static exercise, isolated upper extremity activity and stationary cycling, may not be well documented by activity monitors. The inability to measure this kind of activity configures a limitation to the use of motion sensors in rehabilitation settings where cycling and strength training are performed; however, walking is considered the most important and common type of physical activity performed in daily life $[39,165]$. Walking more in daily life is an important indicator of improvement after rehabilitation protocols, and this can indeed be accurately assessed by motion sensors. Secondly, as previously mentioned, day-to-day variability in habitual physical activity may be large and may hide improvements after interventions, especially in very low levels of activity where improvements may be small but clinically significant. Care must be taken to ensure that studies are sufficiently powered to detect accurately the potential changes after interventions.

\section{Other potentially useful motion sensors}

As described for questionnaires, and also in the case of motion sensors, there are several potentially useful devices which have not yet been used in studies involving COPD patients. Detailed technical information concerning a number of motion sensors can be found in a recently published supplement devoted to this topic [166]. A summary of some widely known devices is provided below.

\section{Pedometers}

A large comparison of 13 models of pedometers was performed by SCHNEIDER et al. [167] over a 24-h period during daily life in healthy adults. One of the best known models of pedometer (Yamax Digi-Walker 200) was used as criterion device. It was chosen because in controlled laboratory settings, this device has consistently been shown to be among the most accurate, besides showing similar accuracy in normal weight, overweight and moderately obese individuals [168]. The models that showed no significant difference when compared with the criterion device were the Kenz Lifecorder, the NewLifestyles NL-2000 (New-Lifestyles Inc., Lee's Summit, MO, USA), the Sportline 330 (Sportline, Yorkers, NY, USA), the Yamax Digi-Walker SW-701 and the criterion device itself, the Yamax Digi-Walker 200. One of these models, the Sportline 330, was shown to have lower reliability in another study [169]. The cost of the pedometers included in the study by SCHNEIDER et al. [167], according to the authors, ranged \$10-200.

The recent technological evolution of pedometers generated the StepWatch (Cyma Corp., Seattle, WA, USA), a microprocessorlinked motion sensor worm at the ankle which not only counts steps, but provides a profile of walking activity. It provides features such as sustained activity (i.e. number of steps achieved during an interval of specified duration) and peak activity index (i.e. highest mean step rate during given intervals of the assessment period). It measures $6.5 \times 5 \times 1.5 \mathrm{~cm}$, weighs $65 \mathrm{~g}$ and costs $\$ 1,995$, which includes activity monitor, docking station and software (August 2005). In stroke patients, the StepWatch was shown to be more accurate than the Caltrac accelerometer [170] for detection of daily ambulatory activity. Furthermore, it was the most accurate among four devices used to detect walking in a study of nursing-home elderly people with dementia [171].

\section{Accelerometers}

\section{Actigraph or MTI/CSA}

This uniaxial accelerometer measures vertical accelerations. It was worn on the waist, wrist or ankle in different studies, although placement at the waist has been suggested to result in higher accuracy [172]. It measures $5 \times 3.8 \times 1.5 \mathrm{~cm}$, weighs $43 \mathrm{~g}$ and costs $\$ 389$ per unit (August 2005), with no reader interface required for the newest model. The output is activity counts (or step counts). It was used in a wide variety of populations, including adults [173] and children [174]. In elderly patients with coronary artery disease, the output from the device was highly correlated with energy expenditure $(r=0.85 ; \mathrm{p}<0.001)$, although the equation chosen to estimate energy expenditure has an important role in the accuracy of the results [175].

\section{Caltrac}

The Caltrac is a very popular uniaxial device which measures vertical accelerations. It counts body movements, whereas 
energy expenditure may be estimated by entering anthropometric data of the wearer. The regular price is $\$ 99.95$ (sale price $\$ 69.95$, August 2005). It measures $7 \times 7 \times 2 \mathrm{~cm}$ and is worn on the waist (hip). It has been used in various populations, including patients with stroke [170], peripheral arterial disease [176] and congestive heart failure [163]. Under laboratory conditions, the Caltrac (as well as the Actigraph/MTI/CSA) showed acceptable validity for estimation of energy expenditure for groups, but there was a wide range of variability concerning both devices on an individual basis [177]. In elderly people under free-living conditions, it has been shown that the Caltrac may significantly underestimate daily physical activity energy expenditure in both in males and females [89].

\section{Mini Motionlogger Actigraph}

The Mini Motionlogger (Ambulatory Monitoring, Ardsley, NY, USA) has multiple programmable parameters and collects information of different variables linked to motor activity, sleep and circadian rhythms. It is worn on the wrist as a watch, and a variety of models are available, with various features (memory size, recording modes, displays, feedback, user input). Prices begin at $\$ 550$ per unit (no software included; August 2005). It measures $6.3 \times 8.9 \times 1.9 \mathrm{~cm}$ and weighs $85 \mathrm{~g}$, although smaller and lighter new models are available. Populations in which the device was used included healthy adults [139] and hyperactive children [178], among others. In elderly people, the Mini Motionlogger showed a correlation of $0.77(p=0.0001)$ with the Tritrac triaxial accelerometer [141].

\section{Armband SenseWear}

Armband SenseWear (BodyMedia Inc., Pittsburgh, PA, USA) is a relatively new device worn on the upper arm. It measures $8.8 \times 5.6 \times 2.1 \mathrm{~cm}$ and weighs $82 \mathrm{~g}$. The device contains a biaxial accelerometer (longitudinal and transverse), although it also collects a variety of data through other multiple sensors (e.g. heat and temperature). It has been introduced as a fitness accessory or an energy consumption monitor since it provides an estimation of energy expenditure based on specific algorithms. It also provides the duration of activities performed by the individual above a determined level of intensity (e.g. 2.5 metabolic equivalents), as well as the number of steps. The price of the device depends on the type of accompanying software: if a "wearer" software (more simple) is chosen, the kit is sold for $€ 800$ (tax not included), whereas if a "research" software (more detailed) is chosen, the price is $€ 3,000$ (tax not included; August 2005). The device was validated against indirect calorimetry in young adults and provided valid estimates of energy expenditure, although it was necessary to apply exercise-specific algorithms to enhance the accuracy of the estimation [179]. A recent study compared estimation of energy cost during treadmill exercise performed by five different motion sensors [180]. Although the Actigraph (CSA) showed the best estimation for walking and jogging and the Tritrac R3D showed the best estimation for running, the Armband showed the best estimation overall, i.e. at most speeds. It has also been used in patients with cardiac disease [181], among others.

\section{ActiReg}

The recently developed ActiReg system (PreMed AS, Oslo, Norway) uses the combined recording of body position and motion to estimate energy expenditure and to describe physical activity patterns. It measures $8.5 \times 4.5 \times 1.5 \mathrm{~cm}$, weighs $60 \mathrm{~g}$, and the current price is $\sim € 440$ for the device and $€ 380$ for the licence of the calculation programme (August 2005). The device can optionally be used simultaneously with equipment for heart rate monitoring. It was validated against DLW in young healthy subjects [161]. The ActiReg provided a valid estimate of energy expenditure at the group level, although with considerable variation at the individual level. Underestimation of energy expenditure was consistently observed, although it was reduced by the addition of heart rate monitoring to the assessment.

\section{Conclusions}

There are different types of motion sensors. They vary from simple and inexpensive devices which basically quantify steps (pedometers) to technologically advanced devices which assess the amount and intensity of physical activity in daily life (multiaxial accelerometers). These devices were shown to provide an accurate overall estimate of physical activity in daily life. However, there is evidence that accelerometers are more accurate for quantification and differentiation of body movement than for estimation of energy expenditure, especially in populations characterised by slow walking speeds. As is seen in subjective methods, more solid evidence concerning reliability, validity and responsiveness of these tools specifically in the COPD population is still lacking. However, technology is rapidly evolving, and further research adding more features to the devices (e.g. heart rate, temperature, upper extremity movement) may further increase insight into daily physical activities.

The selection of a motion sensor for quantification of physical activity level in daily life requires careful consideration of the instrument's convenience, validity, reliability, responsiveness, cost, and, above all, the purpose of its use. Simple pedometers are able to provide information on movement counts, although their use may be limited in slow-walking patients. Since accelerometers are more sensitive for detection of lightintensity activities, they may be more useful in inactive populations, such as COPD patients. More technologically advanced devices, such as multiaxial accelerometers and activity monitors, provide more detailed information on activity patterns, time and intensity of activities.

\section{GENERAL CONCLUSIONS}

In clinical practice, there are situations in which questionnaires are the only available method to assess disability in patients with COPD. Despite their limitations, self-reported methods have practical value, especially in providing the patients' view on their performance in activities of daily living, independence and functional status. Subjective methods for assessment of functional status and objective methods for quantification of daily physical activity provide different but complimentary approaches with which to assess physical activity in daily life. However, caution is necessary when using questionnaires aiming to quantify duration, frequency and intensity of physical activity performed in daily life. The results of these questionnaires may be useful as a group estimate, but they should not be relied upon on an individual basis. More accurate, individualised and detailed information on body 
movement and walking is likely to be available with motion sensors rather than questionnaires, although both motion sensors and questionnaires still present limited validity in estimating energy expenditure during physical activity. The selection of which motion sensor to use for quantification of physical activity in daily life should depend mainly on the purpose of its use. If the purpose is only a simple quantification of steps or counts, a reliable pedometer may be sufficient. However, in a population characterised by inactivity, such as patients with chronic obstructive pulmonary disease, the use of devices more sensitive to light activities (i.e. accelerometers) may result in higher accuracy. In addition, if description of activity patterns, time and intensity of activities is needed, the use of multiaxial devices and activity monitors is indicated in order to provide more accurate, varied and detailed outcomes.

\section{REFERENCES}

1 American College of Sports Medicine Position Stand. The recommended quantity and quality of exercise for developing and maintaining cardiorespiratory and muscular fitness, and flexibility in healthy adults. Med Sci Sports Exerc 1998; 30: 975-991.

2 Garcia-Aymerich J, Farrero E, Felez MA, Izquierdo J, Marrades RM, Anto JM. Risk factors of readmission to hospital for a COPD exacerbation: a prospective study. Thorax 2003; 58: 100-105.

3 Yohannes AM, Baldwin RC, Connolly M. Mortality predictors in disabling chronic obstructive pulmonary disease in old age. Age Ageing 2002; 31: 137-140.

4 Montoye HJ. Introduction: evaluation of some measurements of physical activity and energy expenditure. Med Sci Sports Exerc 2000; 32: Suppl. 9, S439-S441.

5 Restrick LJ, Paul EA, Braid GM, Cullinan P, MooreGillon J, Wedzicha JA. Assessment and follow up of patients prescribed long term oxygen treatment. Thorax 1993; 48: 708-713.

6 Pitta F, Troosters T, Spruit MA, Probst VS, Decramer M, Gosselink R. Characteristics of physical activities in daily life in chronic obstructive pulmonary disease. Am J Respir Crit Care Med 2005; 171: 972-977.

7 Sandland CJ, Singh SJ, Curcio A, Jones PM, Morgan MD. A profile of daily activity in chronic obstructive pulmonary disease. J Cardiopulm Rehabil 2005; 25: 181-183.

8 Global Initiative for Chronic Obstructive Lung Disease. Global Strategy for the Diagnosis, Management and Prevention of Chronic Obstructive Pulmonary Disease. NHLBI/WHO workshop report. Bethesda, National Heart, Lung and Blood Institute, April 2001. Update of the Management Sections. www.goldcopd.com. Date last updated: July 1, 2003. Date last accessed: July 24, 2005.

9 Folgering H, von Herwaarden C. Exercise limitations in patients with pulmonary diseases. Int J Sports Med 1994; 15: 107-111.

10 Lacasse Y, Brosseau L, Milne S, et al. Pulmonary rehabilitation for chronic obstructive pulmonary disease. Cochrane Database Syst Rev 2002; 3: CD003793.

11 Celli BR, MacNee W. Standards for the diagnosis and treatment of patients with COPD: a summary of the ATS/ERS position paper. Eur Respir J 2004; 23: 932-946.
12 Lareau SC, Meek PM, Roos PJ. Development and testing of the modified version of the pulmonary functional status and dyspnea questionnaire (PFSDQ-M). Heart Lung 1998; 27: 159-168.

13 Lareau SC, Carrieri-Kohlman V, Janson-Bjerklie S, Roos PJ. Development and testing of the Pulmonary Functional Status and Dyspnea Questionnaire (PFSDQ). Heart Lung 1994; 23: 242-250.

14 Larson JL, Kapella MC, Wirtz S, Covey MK, Berry J. Reliability and validity of the functional performance inventory in patients with moderate to severe chronic obstructive pulmonary disease. J Nurs Meas 1998; 6: $55-73$.

15 Leidy NK. Psychometric properties of the functional performance inventory in patients with chronic obstructive pulmonary disease. Nurs Res 1999; 48: 20-28.

16 Weaver TE, Narsavage GL, Guilfoyle MJ. The development and psychometric evaluation of the Pulmonary Functional Status Scale: an instrument to assess functional status in pulmonary disease. J Cardiopulm Rehabil 1998; 18: 105-111.

17 Garrod R, Bestall JC, Paul EA, Wedzicha JA, Jones PW. Development and validation of a standardized measure of activity of daily living in patients with severe COPD: the London Chest Activity of Daily Living scale (LCADL). Respir Med 2000; 94: 589-596.

18 Garrod R, Paul EA, Wedzicha JA. An evaluation of the reliability and sensitivity of the London Chest Activity of Daily Living Scale (LCADL). Respir Med 2002; 96: 725-730.

19 Yohannes AM, Roomi J, Winn S, Connolly MJ. The Manchester Respiratory Activities of Daily Living questionnaire: development, reliability, validity, and responsiveness to pulmonary rehabilitation. I Am Geriatr Soc 2000; 48: 1496-1500.

20 Yohannes AM, Greenwood YA, Connolly MJ. Reliability of the Manchester respiratory activities of daily living questionnaire as a postal questionnaire. Age Ageing 2002; 31: 355-358.

21 Yohannes AM, Roomi J, Waters K, Connolly MJ. A comparison of the Barthel index and Nottingham extended activities of daily living scale in the assessment of disability in chronic airflow limitation in old age. Age Ageing 1997; 27: 369-374.

22 Katula JA, Rejeski WJ, Wickley KL, Berry MJ. Perceived difficulty, importance, and satisfaction with physical function in COPD patients. Health Qual Life Outcomes 2004; 2: 18.

23 Carter R, Holiday DB, Grothues C, Nwasuruba C, Stocks J, Tiep B. Criterion validity of the Duke Activity Status Index for assessing functional capacity in patients with chronic obstructive pulmonary disease. J Cardiopulm Rehabil 2002; 22: 298-308.

24 Wigal JK, Creer TL, Kotses H. The COPD Self-Efficacy Scale. Chest 1991; 99: 1193-1196.

25 Morimoto M, Takai K, Nakajima K, Kagawa K. Development of the chronic obstructive pulmonary disease activity rating scale: reliability, validity and factorial structure. Nurs Health Sci 2003; 5: 23-30.

26 Okubadejo AA, O'Shea L, Jones PW, Wedzicha JA. Home assessment of activities of daily living in patients with 
severe chronic obstructive pulmonary disease on longterm oxygen therapy. Eur Respir J 1997; 10: 1572-1575.

27 Bendstrup KE, Ingemann JJ, Holm S, Bengtsson B. Outpatient rehabilitation improves activities of daily living, quality of life and exercise tolerance in chronic obstructive pulmonary disease. Eur Respir J 1997; 10: 2801-2906.

28 Bestall JC, Paul EA, Garrod R, Garnham R, Jones PW, Wedzicha JA. Usefulness of the Medical Research Council (MRC) dyspnoea scale as a measure of disability in patients with chronic obstructive pulmonary disease. Thorax 1999; 54: 581-586.

29 Hodgev V, Kostianev S, Marinov B. University of Cincinnati Dyspnea Questionnaire for Evaluation of Dyspnoea during physical and speech activities in patients with chronic obstructive pulmonary disease: a validation analysis. Clin Physiol Funct Imaging 2003; 23: 269-274.

30 Wedzicha JA, Bestall JC, Garrod R, Garnham R, Paul EA, Jones PW. Randomized controlled trial of pulmonary rehabilitation in severe chronic obstructive pulmonary disease patients, stratified with the MRC dyspnoea scale. Eur Respir J 1998; 12: 363-369.

31 Guyatt GH, Berman LB, Townsend M, Pugsley SO, Chambers LW. A measure of quality of life for clinical trials in chronic lung disease. Thorax 1987; 42: 773-778.

32 Tu SP, McDonell MB, Spertus JA, Steele BG, Fihn SD. A new self-administered questionnaire to monitor healthrelated quality of life in patients with COPD. Ambulatory Care Quality Improvement Project (ACQUIP) Investigators. Chest 1997; 112: 614-622.

33 Jones PW, Quirk FH, Baveystock CM, Littlejohns P. A self-complete measure of health status for chronic airflow limitation. The St. George's Respiratory Questionnaire. Am Rev Respir Dis 1992; 145: 1321-1327.

34 Enright PL, McBurnie MA, Bittner V, et al. The 6-min walk test: a quick measure of functional status in elderly adults. Chest 2003; 123: 387-398.

35 Carter R, Holiday DB, Nwasuruba C, Stocks J, Grothues C, Tiep B. 6-minute walk work for assessment of functional capacity in patients with COPD. Chest 2003; 123: 1408-1415.

36 Caspersen CJ, Powell KE, Christenson GM. Physical activity, exercise, and physical fitness: definitions and distinctions for health-related research. Public Health Rep 1985; 100: 126-131.

37 Steele BG, Belza B, Cain K, Warms C, Coppersmith J, Howard J. Bodies in motion: monitoring daily activity and exercise with motion sensors in people with chronic pulmonary disease. J Rehabil Res Dev 2003; 40: 45-58.

38 Mckenzie TL. Use of direct observation to assess physical activity. In: Welk GJ, ed. Physical Activity Assessments for Health-related Research. Champaign; Human Kinetics Publisher, Inc.; 2002: pp. 179-195.

39 Schutz Y, Weinsier RL, Hunter GR. Assessment of freeliving physical activity in humans: an overview of currently available and proposed new measures. Obes Res 2001; 9: 368-379.

40 Tudor-Locke CE, Myers AM. Challenges and opportunities for measuring physical activity in sedentary adults. Sports Med 2001; 31: 91-100.
41 Speakman JR. The history and theory of the doubly labeled water technique. Am J Clin Nutr 1998; 68: Suppl. 4, 932S-938S.

42 Vanhees L, Lefevre J, Philippaerts R, et al. How to assess physical activity? How to assess physical fitness? Eur J Cardiovasc Prev Rehabil 2005; 12: 102-114.

43 Washburn RA, Heath GW, Jackson AW. Reliability and validity issues concerning large-scale surveillance of physical activity. Res Q Exerc Sport 2000; 71: Suppl. 2, S104-S113.

44 Follick MJ, Ahern DK, Laser-Wolston N. Evaluation of a daily activity diary for chronic pain patients. Pain 1984; 19: 373-382.

45 Friedenreich CM, Courneya KS, Bryant HE. The lifetime total physical activity questionnaire: development and reliability. Med Sci Sports Exerc 1998; 30: 266-274.

46 Kolbe-Alexander TL, Charlton KE, Lambert EV. Lifetime physical activity and determinants of estimated bone mineral density using calcaneal ultrasound in older South African adults. J Nutr Health Aging 2004; 8: 521-530.

47 Bonnefoy M, Normand S, Pachiaudi C, Lacour JR, Laville M, Kostka T. Simultaneous validation of ten physical activity questionnaires in older men: a doubly labeled water study. J Am Geriatr Soc 2001; 49: 28-35.

48 Sarkin JA, Nichols JF, Sallis JF, Calfas KJ. Self-report measures and scoring protocols affect prevalence estimates of meeting physical activity guidelines. Med Sci Sports Exerc 2000; 32: 149-156.

49 Jacobs DR Jr, Ainsworth BE, Hartman TJ, Leon AS. A simultaneous evaluation of 10 commonly used physical activity questionnaires. Med Sci Sports Exerc 1993; 25: 81-91.

50 Leenders NYJM, Sherman M, Nagaraja HN. Comparisons of four methods of estimating physical activity in adult women. Med Sci Sports Exerc 2000; 32: 1320-1326.

51 Shephard RJ. Assessment of physical activity and energy needs. Am J Clin Nutr 1989; 50: 1195-1200.

52 Meek PM, Lareau SC, Anderson D. Memory for symptoms in COPD patients: how accurate are their reports? Eur Respir J 2001; 18: 474-481.

53 Incalzi RA, Gemma A, Marra C, Muzzolon R, Capparella O, Carbonin P. Chronic obstructive pulmonary disease. An original model of cognitive decline. Am Rev Respir Dis 1993; 148: 418-424.

54 Liesker JJ, Postma DS, Beukema RJ, et al. Cognitive performance in patients with COPD. Respir Med 2004; 98: 351-356.

55 Baecke JA, Burema J, Frijters JE. A short questionnaire for the measurement of habitual physical activity in epidemiological studies. Am J Clin Nutr 1982; 36: 936-942.

56 Voorrips LE, Ravelli AC, Dongelmans PC, Deurenberg P, Van Staveren WA. A physical activity questionnaire for the elderly. Med Sci Sports Exerc 1991; 23: 974-979.

57 Coronell C, Orozco-Levi M, Mendez R, RamirezSarmiento A, Galdiz JB, Gea J. Relevance of assessing quadriceps endurance in patients with COPD. Eur Respir J 2004; 24: 129-136.

58 Couillard A, Koechlin C, Cristol JP, Varray A, Prefaut C. Evidence of local exercise-induced systemic oxidative stress in chronic obstructive pulmonary disease patients. Eur Respir J 2002; 20: 1123-1129. 
59 Saey D, Debigare R, LeBlanc P, et al. Contractile leg fatigue after cycle exercise - a factor limiting exercise in patients with chronic obstructive pulmonary disease. Am J Respir Crit Care Med 2003; 168: 425-430.

60 Serres I, Gautier V, Varray A, Prefaut C. Impaired skeletal muscle endurance related to physical inactivity and altered lung function in COPD patients. Chest 1998; 113: 900-905.

61 Philippaerts RM, Westerterp KR, Lefevre J. Doubly labelled water validation of three physical activity questionnaires. Int J Sports Med 1999; 20: 284-289.

62 Philippaerts RM, Westerterp KR, Lefevre J. Comparison of two questionnaires with a tri-axial accelerometer to assess physical activity patterns. Int J Sports Med 2001; 22: 34-39.

63 Walsh MC, Hunter GR, Sirikul B, Gower BA. Comparison of self-reported with objectively assessed energy expenditure in black and white women before and after weight loss. Am J Clin Nutr 2004; 79: 1013-1019.

64 Haas BM, Trew M, Castle PC. Effects of respiratory muscle weakness on daily living function, quality of life, activity levels, and exercise capacity in mild to moderate Parkinson's disease. Am J Phys Med Rehabil 2004; 83: 601-607.

65 Lip GY, Cader MZ, Lee F, Munir SM, Beevers DG. Ethnic differences in pre-admission levels of physical activity in patients admitted with myocardial infarction. Int J Cardiol 1996; 56: 169-175.

66 Pitta F, Troosters T, Spruit MA, Decramer M, Gosselink R. Activity monitoring for assessment of physical activities in daily life in patients with chronic obstructive pulmonary disease. Arch Phys Med Rehabil 2005; 86: 1979-1985.

67 Taylor HL, Jacobs DR Jr, Schucker B, Knudsen J, Leon AS, Debacker G. A questionnaire for the assessment of leisure time physical activities. J Chronic Dis 1978; 31: 741-755.

68 Garcia-Aymerich J, Felez MA, Escarrabill J, et al. Physical activity and its determinants in severe chronic obstructive pulmonary disease. Med Sci Sports Exerc 2004; 36: 1667-1673.

69 Craig CL, Russell SJ, Cameron C. Reliability and validity of Canada's Physical Activity Monitor for assessing trends. Med Sci Sports Exerc 2002; 34: 1462-1467.

70 Sieminski DJ, Cowell LL, Montgomery PS, Pillai SB, Gardner AW. Physical activity monitoring in patients with peripheral arterial occlusive disease. J Cardiopulm Rehabil 1997; 17: 43-47.

71 Slinde F, Arvidsson D, Sjoberg A, Rossander-Hulthen L. Minnesota leisure time activity questionnaire and doubly labeled water in adolescents. Med Sci Sports Exerc 2003; 35: 1923-1928.

72 Washburn RA, Smith KW, Jette AM, Janney CA. The Physical Activity Scale for the Elderly (PASE): development and evaluation. J Clin Epidemiol 1993; 46: 153-162.

73 Gosker HR, Lencer NH, Franssen FM, van der Vusse GJ, Wouters EF, Schols AM. Striking similarities in systemic factors contributing to decreased exercise capacity in patients with severe chronic heart failure or COPD. Chest 2003; 123: 1416-1424.

74 Johansen KL, Painter P, Kent-Braun JA, et al. Validation of questionnaires to estimate physical activity and functioning in end-stage renal disease. Kidney Int 2001; 59: 1121-1127.

75 Caspersen CJ, Bloemberg BP, Saris WH, Merritt RK, Kromhout D. The prevalence of selected physical activities and their relation with coronary heart disease risk factors in elderly men: the Zutphen Study, 1985. Am J Epidemiol 1991; 133: 1078-1092.

76 Slinde F, Ellegard L, Gronberg AM, Larsson S, Rossander-Hulthen L. Total energy expenditure in underweight patients with severe chronic obstructive pulmonary disease living at home. Clin Nutr 2003; 22: 159-165.

77 Last JM, ed. A Dictionary of Epidemiology. 3rd Edn. New York, Oxford University Press Inc., 1995.

78 Kriska A. Ethnic and cultural issues in assessing physical activity. Res Q Exerc Sport 2000; 71: Suppl. 2, S47-S53.

79 Stewart AL, Mills KM, King AC, Haskell WL, Gillis D, Ritter PL. CHAMPS physical activity questionnaire for older adults: outcomes for interventions. Med Sci Sports Exerc 2001; 33: 1126-1141.

80 Ainsworth BE, Leon AS, Richardson MT, Jacobs DR, Paffenbarger RS Jr. Accuracy of the College Alumnus Physical Activity Questionnaire. J Clin Epidemiol 1993; 46: 1403-1411.

81 Uitenbroek DG. Seasonal variation in leisure time physical activity. Med Sci Sports Exerc 1993; 25: 755-760.

82 Folsom AR, Jacobs DR Jr, Caspersen CJ, Gomez-Marin O, Knudsen J. Test-retest reliability of the Minnesota Leisure Time Physical Activity Questionnaire. J Chronic Dis 1986; 39: 505-511.

83 Blair SN, Dowda M, Pate RR, et al. Reliability of longterm recall of participation in physical activity by middleaged men and women. Am J Epidemiol 1991; 133: 266-275.

84 Richardson MT, Leon AS, Jacobs DR Jr, Ainsworth BE, Serfass R. Comprehensive evaluation of the Minnesota Leisure Time Physical Activity Questionnaire. J Clin Epidemiol 1994; 47: 271-281.

85 Hoeymans N, Wouters ER, Feskens EJ, van den Bos GA, Kromhout D. Reproducibility of performance-based and self-reported measures of functional status. J Gerontol $A$ Biol Sci Med Sci 1997; 52: Suppl. 6, M363-M368.

86 Pivarnik JM, Reeves MJ, Rafferty AP. Seasonal variation in adult leisure-time physical activity. Med Sci Sports Exerc 2003; 35: 1004-1008.

87 Trost SG, Pate RR, Freedson PS, Sallis JF, Taylor WC. Using objective physical activity measures with youth: how many days of monitoring are needed? Med Sci Sports Exerc 2000; 32: 426-431.

88 Guillemin F, Bombardier C, Beaton D. Cross-cultural adaptation of health-related quality of life measures: literature review and proposed guidelines. J Clin Epidemiol 1993; 46: 1417-1432.

89 Starling RD, Matthews DE, Ades PA, Poehlman ET. Assessment of physical activity in older individuals: a doubly labeled water study. J Appl Physiol 1999; 86: 2090-2096.

90 Schuit AJ, Schouten EG, Westerterp KR, Saris WH. Validity of the Physical Activity Scale for the Elderly (PASE): according to energy expenditure assessed by the doubly labeled water method. J Clin Epidemiol 1997; 50: 541-546. 
91 Dinger MK, Oman RF, Taylor EL, Vesely SK, Able J. Stability and convergent validity of the Physical Activity Scale for the Elderly (PASE). J Sports Med Phys Fitness 2004; 44: 186-192.

92 Otis RB, Brown AS, Womack CJ, Fonong T, Gardner AW. Relationship between physical activity recall and freeliving daily physical activity in older claudicants. Angiology 2000; 51: 181-188.

93 McDermott MM, Liu K, O’Brien E, et al. Measuring physical activity in peripheral arterial disease: a comparison of two physical activity questionnaires with an accelerometer. Angiology 2000; 51: 91-100.

$94 \mathrm{Ng} \mathrm{AV}$, Kent-Braun JA. Quantitation of lower physical activity in persons with multiple sclerosis. Med Sci Sports Exerc 1997; 29: 517-523.

95 Ainsworth BE, Bassett DR Jr, Strath SJ, et al. Comparison of three methods for measuring the time spent in physical activity. Med Sci Sports Exerc 2000; 32: Suppl. 9, S457-S464.

96 Giantomaso T, Makowsky L, Ashworth NL, Sankaran R. The validity of patient and physician estimates of walking distance. Clin Rehabil 2003; 17: 394-401.

97 Guyatt GH, Kirshner B, Jaeschke R. Measuring health status: what are the necessary measurement properties? J Clin Epidemiol 1992; 45: 1341-1345.

98 Guyatt G, Walter S, Norman G. Measuring change over time: assessing the usefulness of evaluative instruments. $J$ Chronic Dis 1987; 40: 171-178.

99 Mercer K, Follette D, Breslin E, et al. Comparison of functional state between bilateral lung volume reduction surgery and pulmonary rehabilitation: a six-month follow-up study. Int J Surg Investig 1999; 1: 139-147.

100 Pereira MA, FitzerGerald SJ, Gregg EW, et al. A collection of Physical Activity Questionnaires for health-related research. Med Sci Sports Exerc 1997; 29: Suppl. 6, S1-S205.

101 Paffenbarger RS Jr, Blair SN, Lee IM, Hyde RT. Measurement of physical activity to assess health effects in free-living populations. Med Sci Sports Exerc 1993; 25: 60-70.

102 Paffenbarger RS Jr, Wing AL, Hyde RT. Physical activity as an index of heart attack risk in college alumni. Am J Epidemiol. 1978; 108: 161-175.

103 Sesso HD, Paffenbarger RS Jr, Lee IM. Physical activity and coronary heart disease in men: The Harvard Alumni Health Study. Circulation 2000; 102: 975-980.

104 Lee IM, Paffenbarger RS Jr. Physical activity and stroke incidence: the Harvard Alumni Health Study. Stroke 1998; 29: 2049-2054.

105 Paffenbarger RS Jr, Lee IM, Kampert JB. Physical activity in the prevention of non-insulin-dependent diabetes mellitus. World Rev Nutr Diet 1997; 82: 210-218.

106 Lee IM, Paffenbarger RS Jr. Physical activity and its relation to cancer risk: a prospective study of college alumni. Med Sci Sports Exerc 1994; 26: 831-837.

107 Paffenbarger RS Jr, Lee IM. Intensity of physical activity related to incidence of hypertension and all-cause mortality: an epidemiological view. Blood Press Monit 1997; 2: 115-123.

108 Montoye HJ. Estimation of habitual physical activity by questionnaire and interview. Am J Clin Nutr 1971; 24: 1113-1118.
109 Reiff GG, Montoye HJ, Remington RD, Napier JA Metzner HL, Epstein FH. Assessment of physical activity by questionnaire and interview. J Sports Med Phys Fitness 1967; 7: 135-142.

110 Conway JM, Irwin ML, Ainsworth BE. Estimating energy expenditure from the Minnesota Leisure Time Physical Activity and Tecumseh Occupational Activity questionnaires - a doubly labeled water validation. J Clin Epidemiol 2002; 55: 392-399.

111 Blair SN, Haskell WL, Ho P, et al. Assessment of habitual physical activity by a seven-day recall in a community survey and controlled experiments. Am J Epidemiol 1985; 122: 794-804.

112 Johnson MF, Nichols JF, Sallis JF, Calfas KJ, Hovell MF. Interrelationships between physical activity and other health behaviors among university women and men. Prev Med 1998; 27: 536-544.

113 Sallis JF, Haskell WL, Wood PD, Fortmann SP, Rogers T, Blair SN, Paffenbarger RS Jr. Physical activity assessment methodology in the Five-City Project. Am J Epidemiol 1985; 121: 91-106.

114 Miller DJ, Freedson PS, Kline GM. Comparison of activity levels using the Caltrac accelerometer and five questionnaires. Med Sci Sports Exerc 1994; 26: 376-382.

115 Tudor-Locke CE, Myers AM. Challenges and opportunities for measuring physical activity in sedentary adults. Sports Med 2001; 31: 91-100.

116 Westerterp KR. Physical activity assessment with accelerometers. Int J Obes Relat Metab Disord 1999; 23: Suppl. 3, S45-S49.

117 Bassett DR Jr. Validity and reliability issues in objective monitoring of physical activity. Res Q Exerc Sport 2000; 71 Suppl. 2, S30-S36.

118 Mathie MJ, Coster AC, Lovell NH, Celler BG. Accelerometry: providing an integrated, practical method for long-term, ambulatory monitoring of human movement. Physiol Meas 2004; 25: Suppl. 2, R1-R20.

119 Tudor-Locke C, Williams JE, Reis JP, Pluto D. Utility of pedometers for assessing physical activity: convergent validity. Sports Med 2002; 32: 795-808.

120 Schonhofer B, Ardes P, Geibel M, Kohler D, Jones PW. Evaluation of a movement detector to measure daily activity in patients with chronic lung disease. Eur Respir J 1997; 10: 2814-2819.

121 Coronado $M$, Janssens JP, de Muralt B, Terrier $\mathrm{P}$, Schutz Y, Fitting JW. Walking activity measured by accelerometry during respiratory rehabilitation. J Cardiopulm Rehabil 2003; 23: 357-364.

122 Singh S, Morgan MD. Activity monitors can detect brisk walking in patients with chronic obstructive pulmonary disease. J Cardiopulm Rehabil 2001; 21: 143-148.

123 Sewell L, Singh SJ, Williams JE, Collier R, Morgan MD. Can individualized rehabilitation improve functional independence in elderly patients with COPD? Chest 2005; 128: 1194-1200.

124 Mercken EM, Hageman GJ, Schols AM, Akkermans MA, Bast A, Wouters EF. Rehabilitation decreases exerciseinduced oxidative stress in chronic obstructive pulmonary disease. Am J Respir Crit Care Med 2005; 172: 994-1001. 
125 Goris AH, Meijer EP, Kester A, Westerterp KR. Use of a triaxial accelerometer to validate reported food intakes. Am J Clin Nutr 2001; 73: 549-553.

126 Goris AH, Vermeeren MA, Wouters EF, Schols AM, Westerterp KR. Energy balance in depleted ambulatory patients with chronic obstructive pulmonary disease: the effect of physical activity and oral nutritional supplementation. Br J Nutr 2003; 89: 725-731.

127 Steele BG, Holt L, Belza B, Ferris S, Lakshminaryan S, Buchner DM. Quantitating physical activity in COPD using a triaxial accelerometer. Chest 2000; 117: 1359-1367.

128 Steele BG, Belza B, Hunziker J, et al. Monitoring daily activity during pulmonary rehabilitation using a triaxial accelerometer. J Cardiopulm Rehabil 2003; 23: 139-142.

129 Belza B, Steele BG, Hunziker J, Lakshminaryan S, Holt L, Buchner DM. Correlates of physical activity in chronic obstructive pulmonary disease. Nurs Res 2001; 50: 195-202.

130 Behnke M, Wewel AR, Kirsten D, Jorres RA, Magnussen $H$. Exercise training raises daily activity stronger than predicted from exercise capacity in patients with COPD. Respir Med 2005; 99: 711-717.

131 Pitta F, Troosters T, Probst VS, Spruit MA, Decramer M, Gosselink R. Physical activity and hospitalization for exacerbation of chronic obstructive pulmonary disease. Chest 2006; 129: 536-544.

132 Iwane M, Arita M, Tomimoto S, et al. Walking 10,000 steps/day or more reduces blood pressure and sympathetic nerve activity in mild essential hypertension. Hypertens Res 2000; 23: 573-580.

133 Chan CB, Ryan DA, Tudor-Locke C. Health benefits of a pedometer-based physical activity intervention in sedentary workers. Prev Med 2004; 39: 1215-1222.

134 Wyatt HR, Peters JC, Reed GW, Barry M, Hill JO. A Colorado statewide survey of walking and its relation to excessive weight. Med Sci Sports Exerc 2005; 37: 724-730.

135 Cyarto EV, Myers AM, Tudor-Locke C. Pedometer accuracy in nursing home and community-dwelling older adults. Med Sci Sports Exerc 2004; 36: 205-209.

136 Tudor-Locke C, Ainsworth BE, Thompson RW, Matthews CE. Comparison of pedometer and accelerometer measures of free-living physical activity. Med Sci Sports Exerc 2002; 34: 2045-2051.

137 The Anatomy of a Pedometer, 2004. www.pedometers. com. Date last accessed: July 24, 2005.

138 Freedson PS, Miller K. Objective monitoring of physical activity using motion sensors and heart rate. Res $Q$ Exerc Sport 2000; 71: S21-S29.

139 Patterson SM, Krantz DS, Montgomery LC, Deuster PA, Hedges SM, Nebel LE. Automated physical activity monitoring: validation and comparison with physiological and self-report measures. Psychophysiology 1993; 30: 296-305.

140 Le Masurier GC, Tudor-Locke C. Comparison of pedometer and accelerometer accuracy under controlled conditions. Med Sci Sports Exerc 2003; 35: 867-871.

141 Kochersberger G, McConnell E, Kuchibhatla MN, Pieper C. The reliability, validity, and stability of a measure of physical activity in the elderly. Arch Phys Med Rehabil 1996; 77: 793-795.
142 Powell SM, Rowlands AV. Intermonitor variability of the RT3 accelerometer during typical physical activities. Med Sci Sports Exerc 2004; 36: 324-330.

143 Hendelman D, Miller K, Baggett C, Debold E, Freedson P. Validity of accelerometry for the assessment of moderate intensity physical activity in the field. Med Sci Sports Exerc 2000; 32: Suppl. 9, S442-S449.

144 Hartsell H, Fitzpatrick D, Brand R, Frantz R, Saltzman C. Accuracy of a custom-designed activity monitor: implications for diabetic foot ulcer healing. J Rehabil Res Dev 2002; 39: 395-400.

145 Schutz Y, Weinsier S, Terrier P, Durrer D. A new accelerometric method to assess the daily walking practice. Int J Obes Relat Metab Disord 2002; 26: 111-118.

146 Richardson MT, Leon AS, Jacobs DR Jr, Ainsworth BE, Serfass R. Ability of the Caltrac accelerometer to assess daily physical activity levels. J Cardiopulm Rehabil 1995; 15: 107-113.

147 Bouten CV, Verboeket-van de Venne WP, Westerterp KR, Verduin M, Janssen JD. Daily physical activity assessment: comparison between movement registration and doubly labeled water. J Appl Physiol 1996; 81: 1019-1026.

148 Matthews CE, Ainsworth BE, Thompson RW, Bassett DR Jr. Sources of variance in daily physical activity levels as measured by an accelerometer. Med Sci Sports Exerc 2002; 34: 1376-1381.

149 Levin S, Jacobs DR Jr, Ainsworth BE, Richardson MT, Leon AS. Intra-individual variation and estimates of usual physical activity. Ann Epidemiol 1999; 9: 481-488.

150 Gretebeck RJ, Montoye HJ. Variability of some objective measures of physical activity. Med Sci Sports Exerc 1992; 24: 1167-1172.

151 Tudor-Locke C, Burkett L, Reis JP, Ainsworth BE, Macera CA, Wilson DK. How many days of pedometer monitoring predict weekly physical activity in adults? Prev Med 2005; 40: 293-298.

152 Sherman WM, Morris DM, Kirby TE, et al. Evaluation of a commercial accelerometer (Tritrac-R3 D) to measure energy expenditure during ambulation. Int J Sports Med 1998; 19: 43-47.

153 Meijer GA, Westerterp KR, Koper $H$, ten Hoor F. Assessment of energy expenditure by recording heart rate and body acceleration. Med Sci Sports Exerc 1989; 21: 343-347.

154 Leenders NY, Sherman WM, Nagaraja HN, Kien CL. Evaluation of methods to assess physical activity in freeliving conditions. Med Sci Sports Exerc 2001; 33: 1233-1240.

155 Campbell KL, Crocker PR, McKenzie DC. Field evaluation of energy expenditure in women using Tritrac accelerometers. Med Sci Sports Exerc 2002; 34: 1667-1674.

156 Bassett DR Jr, Ainsworth BE, Swartz AM, Strath SJ, O'Brien WL, King GA. Validity of four motion sensors in measuring moderate intensity physical activity. Med Sci Sports Exerc 2000; 32: Suppl. 9, S471-S480.

157 Jakicic JM, Winters C, Lagally K, Ho J, Robertson RJ, Wing RR. The accuracy of the TriTrac-R3D accelerometer to estimate energy expenditure. Med Sci Sports Exerc 1999; 31: 747-754. 
158 Leenders NY, Nelson TE, Sherman WM. Ability of different physical activity monitors to detect movement during treadmill walking. Int J Sports Med 2003; 24: 43-50.

159 Plasqui G, Joosen AM, Kester AD, Goris AH, Westerterp KR. Measuring free-living energy expenditure and physical activity with triaxial accelerometry. Obes Res 2005; 13: 1363-1369.

160 Brage S, Brage N, Franks PW, et al. Branched equation modeling of simultaneous accelerometry and heart rate monitoring improves estimate of directly measured physical activity energy expenditure. I Appl Physiol 2004; 96: 343-351.

161 Hustvedt BE, Christophersen A, Johnsen LR, et al. Description and validation of the ActiReg: a novel instrument to measure physical activity and energy expenditure. Br J Nutr 2004; 92: 1001-1008.

162 Strath SJ, Bassett DR Jr, Swartz AM, Thompson DL. Simultaneous heart rate-motion sensor technique to estimate energy expenditure. Med Sci Sports Exerc 2001; 33: 2118-2123.

163 Gottlieb SS, Fisher ML, Freudenberger R, et al. Effects of exercise training on peak performance and quality of life in congestive heart failure patients. J Card Fail 1999; 5: 188-194.

164 van Stel HF, Colland VT, Heins NL, RijssenbeekNouwens LH, Everaerd W. Assessing inpatient pulmonary rehabilitation using the patient's view of outcome. J Cardiopulm Rehabil 2002; 22: 201-210.

165 Yusuf HR, Croft JB, Giles WH, et al. Leisure-time physical activity among older adults. United States, 1990. Arch Intern Med 1996; 156: 1321-1326.

166 Troiano RP. A timely meeting: objective measurement of physical activity. Med Sci Sports Exerc 2005; 37: Suppl. 11, S487-S489.

167 Schneider PL, Crouter SE, Bassett DR. Pedometer measures of free-living physical activity: comparison of 13 models. Med Sci Sports Exerc 2004; 36: 331-335.

168 Swartz AM, Bassett DR Jr, Moore JB, Thompson DL, Strath SJ. Effects of body mass index on the accuracy of an electronic pedometer. Int J Sports Med 2003; 24: 588-592.

169 Schneider PL, Crouter SE, Lukajic O, Bassett DR Jr. Accuracy and reliability of 10 pedometers for measuring steps over a 400-m walk. Med Sci Sports Exerc 2003; 35: 1779-1784.

170 Haeuber E, Shaughnessy M, Forrester LW, Coleman KL, Macko RF. Accelerometer monitoring of home- and community-based ambulatory activity after stroke. Arch Phys Med Rehabil 2004; 85: 1997-2001.

171 Algase DL, Beattie ER, Leitsch SA, Beel-Bates CA. Biomechanical activity devices to index wandering behavior in dementia. Am J Alzheimer's Dis Other Demen 2003; 18: 85-92.

172 Swartz AM, Strath SJ, Bassett DR Jr, O'Brien WL, King GA, Ainsworth BE. Estimation of energy expenditure using CSA accelerometers at hip and wrist sites. Med Sci Sports Exerc 2000; 32: Suppl. 9, S450-S456.

173 Brage S, Wedderkopp N, Franks PW, Andersen LB, Froberg K. Reexamination of validity and reliability of the CSA monitor in walking and running. Med Sci Sports Exerc 2003; 35: 1447-1454.

174 Trost SG, Sirard JR, Dowda M, Pfeiffer KA, Pate RR. Physical activity in overweight and nonoverweight preschool children. Int J Obes Relat Metab Disord 2003; 27: 834-839.

175 Ekelund U, Tingstrom P, Kamwendo K, et al. The validity of the Computer Science and Applications activity monitor for use in coronary artery disease patients during level walking. Clin Physiol Funct Imaging 2002; 22: 248-253.

176 McDermott MM, Ohlmiller SM, Liu K, et al. Gait alterations associated with walking impairment in people with peripheral arterial disease with and without intermittent claudication. J Am Geriatr Soc 2001; 49: 747-754.

177 Melanson EL Jr, Freedson PS. Validity of the Computer Science and Applications, Inc. (CSA) activity monitor. Med Sci Sports Exerc 1995; 27: 934-940.

178 Miller LG, Kraft IA. Application of actigraphy in the clinical setting: use in children with attention-deficit hyperactivity disorder. Pharmacotherapy 1994; 14: 219-223.

179 Jakicic JM, Marcus M, Gallagher KI, Randall C, Thomas E, Goss FL, Robertson RJ. Evaluation of the SenseWear Pro Armband to assess energy expenditure during exercise. Med Sci Sports Exerc 2004; 36: 897-904.

180 King GA, Torres N, Potter C, Brooks TJ, Coleman KJ. Comparison of activity monitors to estimate energy cost of treadmill exercise. Med Sci Sports Exerc 2004; 36: 1244-1251.

181 Cole PJ, LeMura LM, Klinger TA, Strohecker K, McConnell TR. Measuring energy expenditure in cardiac patients using the Body Media Armband versus indirect calorimetry. A validation study. J Sports Med Phys Fitness 2004; 44: 262-271. 